\title{
Competitividade digital
}

mercado de produção de softwares cresce em todo o mun-
do, e a situação é favorável aos países emergentes, incluin-
do o Brasil. o fato é explicado pela crescente pressão que as multinacionais norte-americanas e européias vêm recebendo para diversificarem suas cadeias produtivas em regiões de menor risco, com mão-de-obra barata e razoavelmente qualificada. 0 artigo analisa a situação dessa indústria no Brasil, destaca os fatores internos e externos favoráveis ao seu desenvolvimento e os principais desafios a serem superados para a elevação de sua vantagem competitiva futura.

por llan Avrichir ESPM eJairo Avitchir ASSESPRO

0 aumento da exportação de serviços de software por países emergentes éuma das mais notáveis tendências na evolução da divisão internacional de trabal ho nos últimos anos. Em particular, merecem destaque exemplos como Índia, que, no intervalo entre 1984 e 2002, elevou suas exportações de US\$ 22 milhões para mais de US\$ 9 bilhões; Irlan- da, que em 1991 exportava US\$2,4 bilhões, passou para a cifra de US\$ 17,3 bilhões em 2003; elsrael, cujas exportações, em 1991, chegavam a US\$ 110 milhões, passou a um volume de US\$2,5 bilhões no ano 2000.

Apesar de as previsões variarem bastante, a maioria dos observadores estima que a terceirização internacional 
de processos empresariais vai continuar a crescer a taxas de $30 \%$ ao ano até 2008 . E o mais importante é que 0 motor desse crescimento é atribuído aos serviços relacionados com a produção de software. Tal situação oferece aos países emergentes, entre eles o Brasil, um número grande de oportunidades e benefícios, principalmente os relacionados à criação de empregos qualificados, ao aumento de salários e à incorporação de competências.

O cenário i nternaci onal . Dois importantes acontecimentos no cenário mundial têm influenciado decisivamente no aumento das exportações de software por parte de países emergentes, como o Brasil. Em primeiro lugar, a Índia, país considerado líder inconteste do mercado de produção de software e serviços vinculados à tecnologia da informação, como call centers, está passando por transformações significativas em sua indústria.

U ma delas refere-se ao aumento dos salários dos profissionais indianos, que têm crescido a taxas muito superiores à média mundial. A conseqüência desse fato é 0 aumento da rotatividade de pessoal, que no caso indiano varia de $15 \%$ a $30 \%$ em algumas empresas. Uma segunda transformação está ligada ao aumento das preocupações das indústrias norte-americanas e européias lá instaladas por conta dos atentados terroristas verificados naquele país. Tendo em vista que a concentração dessas empresas é grande na região, elas vêm procurando diversificar seus riscos migrando para outros países emergentes, livres de problemas sociais como este. Evidentemente, tal fato diversifica as estratégias de investi-
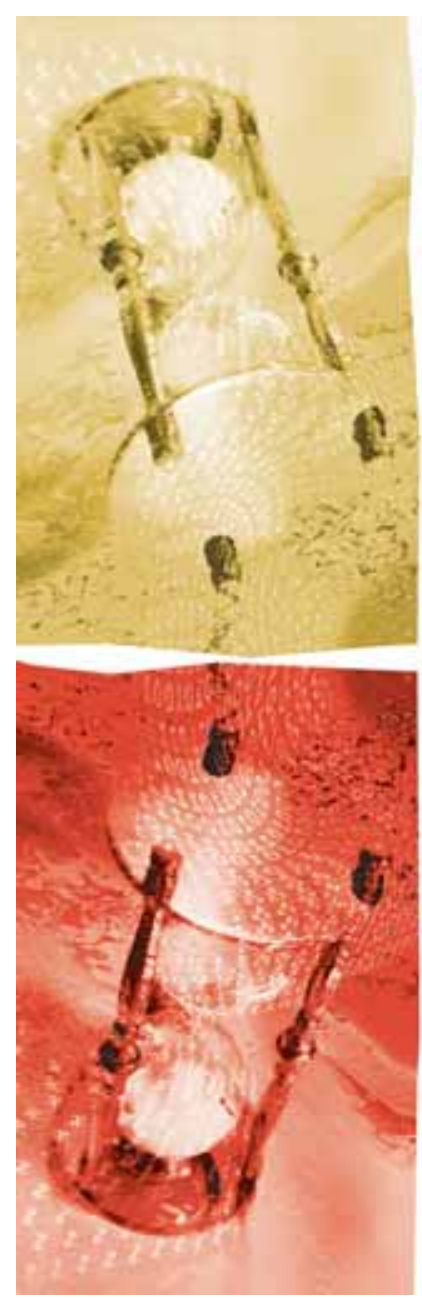
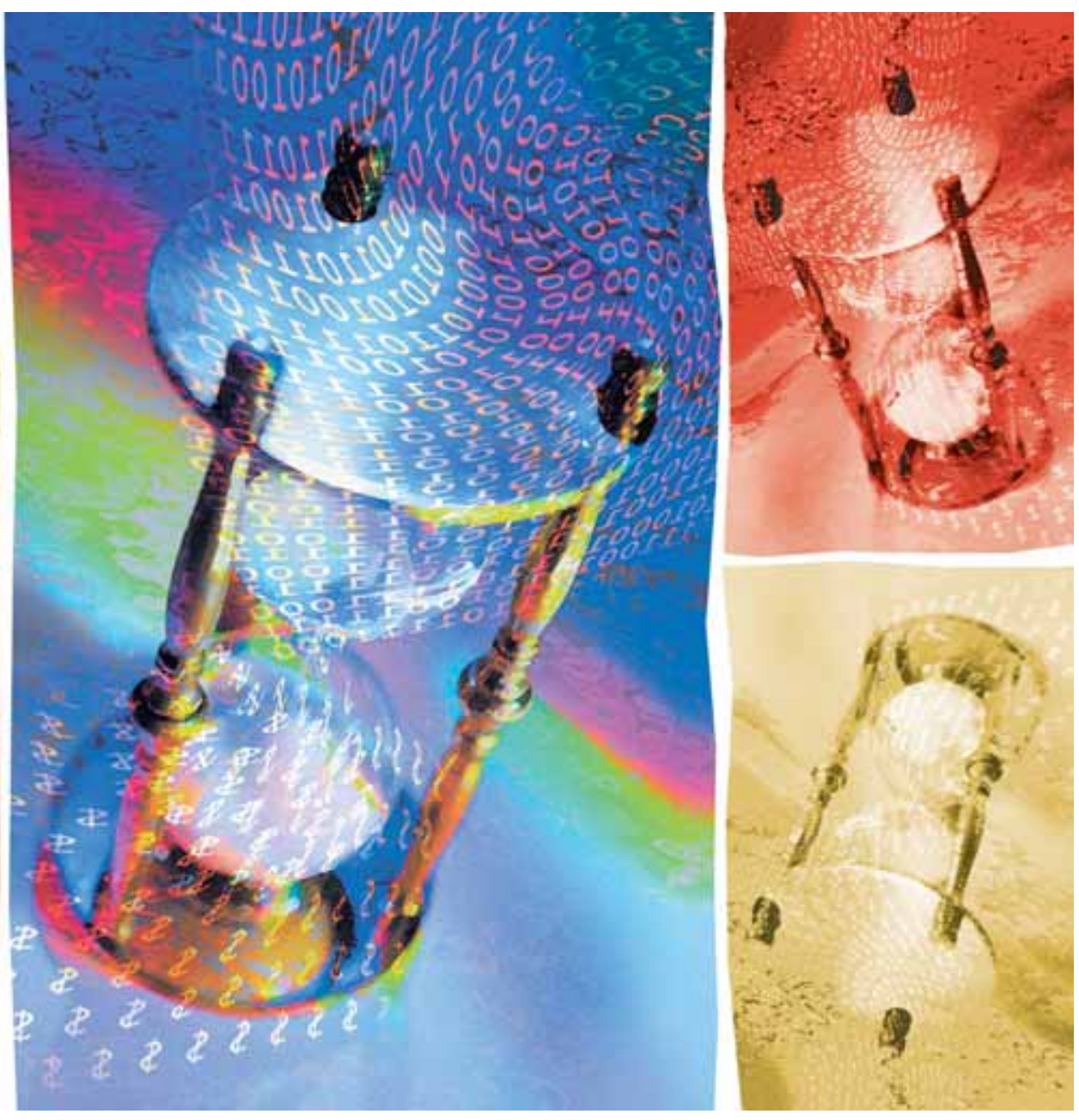
mento dessas empresas, abrindo a oportunidade para outros países emergentes.

Um segundo fato, ainda no cenário mundial, tem influenciado o mercado de produção de software. Trata-se das contínuas pressões que vêm recebendo as empresas norte-americanas para transferirem partes do processo de desenvolvimento de software para países emergentes, dentro de uma estratégia global de ramificação de suas cadeias produtivas. Acionistas e fundos de investimento têm sido os principais responsáveis por essas pressões.

O cenário brasi l ei ro. Se as duas transformações, anteriormente analisadas, têm exercido importante influência sobre a dinâmica da indústria de softwares, principalmente no sentido de ampliar os fluxos de investimento em outros países emergentes que não, por exemplo, os tradicionais (como a Índia), o mesmo pode ser dito com respeito a transformações na indústria de softwares no Brasil. Em específico, observamos duas transformações, as quais vêm contribuindo para a el evação da competitividade de nossa indústria de software local.

Em primeiro lugar, observamos uma desaceleração recente do mercado de software no Brasil. Nos últimos dez anos, esse mercado passou por diversos ciclos de aquecimento de demanda. Primeiro, a onda de fusões e aquisições no setor bancário; depois, as privatizações e fusões na área de telecomunicações; em seguida, fatos como o bug do milênio, a implantação do Sistema Brasileiro de Pagamentos; e, por fim, a adoção de ERPs pelas empresas e a automação de pontosde-venda.

0 problema é que essas ondas parecem ter passado. Se, por um lado, permitiram uma acumulação de conhecimentos no setor, fundamental para a competição no cenário internacional, por outro diminuíram a pressão para atuar no mercado externo. No entanto, como agora não se esboça qualquer reaquecimento do mercado interno, as empresas estão tendo de mirar outros mercados com o intuito de se expandirem. 0 mercado externo passa a ser, portanto, condição de sobrevivência dessas empresas.
Em segundo lugar deve ser citada a importância da Lei $n .08248$ que vigorou no país de 1993 a 2001 e foi substituída pela Lei n. 10176 em 2001. Essa lei, conhecida como Lei de Informática, concede isenção parcial de IPI para fabricantes de equipamentos de tecnologia, que, em contrapartida, devem investir cerca de $5 \%$ de seu faturamento em centros de pesquisa e desenvolvimento locais. Estima-se que, no período de 1993 a 2001, perto de 250 grandes empresas multinacionais do setor estabelecidas no Brasil, além de empresas nacionais como a Itautec, investiram cerca de $\mathrm{R} \$ 3$ bilhões em pesquisa e desenvolvimento em função da Lei. A maior parte desses recursos foi direcionada para o desenvolvimento de software.

Desafios Iocais. A pesar da aparente favorabilidade dos cenários internacional e local para a indústria de software, o fato é que o país ainda está longe de atingir o nível esperado de exportações. Ó rgãos federais e associações de fomento vêm anunciando que uma meta de exportação razoável para o país seria al go da ordem de US $\$ 2$ bilhões ao ano em 2007. Na prática, porém, de acordo com as mais otimistas das avaliações, o país não chega a exportar mais do que US\$ 400 milhões ao ano.

\section{processos empresariais vai continuar a crescer a taxas de 30\% ao ano até 2008.}

As análises sobre as razões dessa defasagem começam a surgir em diversas revistas especializadas, como Exame e Carta Capital. 0 fato é que não observamos ainda um consenso sobre as causas do problema. 0 que se observa é um conjunto disperso de indicadores e experiências, a maior parte destas obtidas das próprias empresas atuantes no setor (ver quadro). M esmo assim, podemos observar três conjuntos de obstáculos que dificultam o crescimento do volume de exportações de nossa indústria de software, que passamos a analisar a seguir. 
0 primeiro conjunto diz respeito à ausência de financiamentos a custos internacionalmente competitivos, à rigidez de nossa legislação trabalhista, às barreiras fiscais que se traduzem pela elevada incidência de impostos sobre a cadeia produtiva e sobre a exportação de serviços e às deficiências de formação de mão-de-obra.

0 segundo conjunto refere-se à reputação das empresas de software de outros países. Pelo fato de terem sido as primeiras a entrarem nesse mercado, as indústrias indianas, irlandesas e israelenses, por exemplo, detêm a esta altura recursos de marca e imagem de difícil imitação. No ramo de serviços, a teoria mostra que os clientes potenciais têm grande dificuldade em avaliar, de antemão, a qualidade dos serviços que adquirem e, por essa razão, tendem a valorizar a reputação das empresas como um tipo de garantia. Sabemos que a reputação é um recurso muito mais valioso para as empresas de serviço do que para as do ramo industrial tradicional. Desse ponto de vista, as empresas brasileiras estão em franca desvantagem. se caso, as empresas brasileiras têm hoje pela frente um grande desafio no sentido de desenvolverem capacidades organizacionais compatíveis com o tipo de indústria em que estão atuando e competindo.

O futuro da indústria. N este ponto o leitor pode estar se indagando sobre como nossa indústria de software poderá enfim alcançar o nível de desempenho e competitividade internacional coerentes com o potencial do país nesta área. Podemos, para finalizar este artigo, destacar al gumas hipóteses sobre o futuro dessa indústria no país.

Em primeiro lugar, avançar na sofisticação de competências organizacionais. Apesar de as empresas brasileiras apresentarem hoje avanços importantes em relação há alguns anos, o fato é que, como visto anteriormente, as concorrentes internacionais o fizeram em velocidade e intensidade superiores. Isso coloca para nossas empresas desafios mais rigorosos, sobretudo no que se refere à correção de sua defasagem com relação às concorrentes principais.

Para piorar a situação, há novos entrantes neste setor, fato que se observa principalmente nos mercados chinês, russo, filipino e dos países do Leste Europeu.

Em segundo lugar, é preciso maior apoio financeiro do governo a essa indústria. Além do apoio financeiro, medidas como a inclusão de benefícios fiscais às empresas exportadorastambém se revelam experiências de elevado impacto positivo. Ações concretas já podem
Um último conjunto de obstáculos de nossa indústria está ligado a seu baixo desenvolvimento de capacidades específicas. As empresas indianas, irlandesas e israelenses, para ficar ainda com esses exemplos, desenvolveram ao longo do tempo competências de controle de processos, de gestão de equipes multiculturais, tornando-se altamente especializadas. Esse fato aumenta, e muito, sua produtividade e tornam seus processos de vantagens competitivas menos dependentes da liderança em custo. Nes- ser observadas nesse sentido, como a isenção fiscal proposta pela Medida Provisória 255 e a liberação de linhas de crédito a juros inferiores aos do mercado para al gumas empresas do setor, mostram que o governo está sensível aos desafios dessa indústria.

Para encerrar, além de tudo o que já foi escrito, talvez um ponto essencial mereça destaque: nessa indústria, a principal fonte de sobrevivência é a velocidade. Veja-se o caso da certificação CMM nível 5. Trata-se do 


\section{Retrato do setor}

Existem três tipos de empresas atuando no setor de produção e exportação de softwares no país: multinacionais diretamente focadas em desenvolvimento tecnológico; multinacionais de outras áreas que não a tecnológica, mas com investimentos em pesquisa e desenvolvimento; e empresas brasileiras de tecnologia. Vejamos cada uma delas a seguir.

Multinacionais de tecnologia de informação instaladas no Brasil são representadas por empresas como Motorola, HP, Dell, Nokia, Ericson, Siemens e Samsung. Essas empresas estão criando e expandindo centros de desenvolvimento de software e trazendo para o Brasil atividades que antes eram feitas em suas matrizes.

Um exemplo desse tipo de empresa é a Dell Computadores, que abriu sua filial no Brasil em 1999. A partir de 2000 , criou aqui o Centro Global de Desenvolvimento de Software, ou GDC, concebido com o intuito de trazer para o país uma parte das atividades de desenvolvimento das ferramentas de uso global. Em 2002, o centro foi transferido para o parque tecnológico da Pontifícia Universidade Católica do Rio Grande do Sul (TecnoPUC), ocupando uma área de mais de 1.400 metros quadrados. Em 2003, o GDC conquistou a certificação CMM nível 2 , sendo o primeiro na Dell em todo o mundo a atingir tal padrão. Atualmente, existem na Dell quatro centros de desenvolvimento de software: nos Estados Unidos, na Índia, na Rússia e no Brasil. 0 centro de Porto Alegre tem mais de 300 profissionais trabalhando em período integral.

As multinacionais de outras áreas, que não de tecnologia, com filiais no país são empresas que anunciaram a criação ou ampliação de centros de desenvolvimento de software ou de realização de processos de negócios no Brasil. Entre elas estão a Renault, a Johnson \& Johnson, a Rhodia, a Exxon e a Sonae.
A Renault e a Rhodia, por exemplo, decidiram centralizar partes do desenvolvimento de SAP Global no Brasil. A Johnson \& Johnson começou por fazer parte da manutenção de sistemas legados em São José dos Campos. 0 grupo Sonae abriu uma empresa separada, a Tlantic, sediada no TecnoPUC, em Porto Alegre, para desenvolver software para a matriz em Portugal e tem intenção de transformar a nova empresa em um centro de resultados, exportando serviços de desenvolvimento de software. ATlantic aumentou o número de profissionais em um ano de 40 para mais de 150 e certificou-se em CMM nível 2 .

No caso dessas empresas, os fatores que parecem estar determinando os movimentos são justamente a pressão para aumentarem a parcela de atividades em países em desenvolvimento e 0 desejo de não concentrarem suas atividades apenas na Índia. Um outro fator que também explica esse movimento é a crescente padronização e globalização dos sistemas de informação dessas multinacionais.

Por fim, entre as empresas brasileiras que vêm contribuindo para o desenvolvimento da indústria de software no país incluímos a Stefanini, CPM, Procwork, Brasscom, C.P.M, Microsiga, Datasul e Módulo. Tais empresas têm como atividade principal a prestação de serviços na área de software, tendo há muito tempo vislumbrado oportunidades de exportação na área e realizando importantes investimentos.

Vejamos, por exemplo, o caso da Stefanini. Ela incorporou seu primeiro escritório na Flórida em 2001. Naquele ano, conseguiu dois contratos. Em 2003, mais 2; em 2004, 4 e, em 2005, apenas no primeiro semestre, outros 10 contratos. Quase todos os clientes da empresa no exterior são filiais de empresas multinacionais para as quais ela começou prestando serviços no Brasil, evoluindo desse contato inicial até suas matrizes nos Estados Unidos. certificado de qualidade na produção e gerenciamento de software mais valorizado pela indústria mundial. De todas as empresas atuantes no país, apenas duas possuem esse certificado; na Índia, apenas na região de Bangalore, há cinqüenta emp resas certificadas. Esse é um pequeno exemplo da distância que nos separa dos líderes do setor. Sem um ritmo acelerado de investimento e desenvolvimento de nossa indústria, dificilmente conseguiremos vencer essa distância.

\section{Ilan Avidhir}

Prof. e coord. do Departamento de Organizações e RH da ESPM e prof. do MBA do IBMEC-SP

Doutor em Administração de Empresas pela FGV-EAESP

E-mail: iavrichir@espm.br

\section{Jairo Avitchir}

ASSESPRO Rio Grande do Sul

E-mail: jairo_avritchir@uol.com.br 